\title{
New technology for increasing the sustainability of urban transport operation
}

\author{
I. S. Maslennikova ${ }^{1} \&$ T. Yu. Grishchenko ${ }^{2}$ \\ ${ }^{1}$ Saint-Petersburg State University of Economics, Russia \\ ${ }^{2}$ National Research University, \\ Higher School of Economics (HSE), Russia
}

\begin{abstract}
A new environmentally friendly method to improve the properties of soils by the introduction of $1-3 \%$ non-toxic amino complex compounds (ACC) produced from toxic industrial waste was developed. The relationship between the clayey soils' mineral composition and the efficiency of their melioration was defined. A new technology to synthesize non-toxic amino complex compounds from toxic industrial waste was presented and reviewed from the perspective of their application in improving the quality of high-moist clayey soils in road and airfield construction.

Keywords: transportation facilities, road construction, clayey soil, frost heave, toxic waste, ecology, amino complex compounds, hydrophobization.
\end{abstract}

\section{Introduction}

Highways are a qualitative indicator of the development of regions and the country as a whole. Practice shows that the countries, where the transport network is sufficiently developed, are in safe financial condition, as the roads affect the mobility of cargo delivery, tourism and others business activity. Therefore, the maintenance of roads in an excellent condition is the key to success for any country.

Frost heave is a serious danger in road construction and operation. Commonly spread soils in Russia are clayey and their moisturizing leads to a deterioration of their physical and mechanical properties: excessive water absorption, swelling, stickiness and reduced strength characteristics. Additionally, more than $65 \%$ of 
soils in the country are permafrost and this has a detrimental effect on the roads [1].

Compared to the initial investment, astronomical sums are spent every year on road repairing and this adversely affects the budget of the Russian Federation. Studies have revealed that road embankments erected years ago are not sufficient for modern loadings and car specifications and currently the road surfaces break up exponentially. In this regard, the task of improving the properties of clayey soils is extremely important.

The present work highlights two interrelated issues: a new technology to improve the properties of the clayey soils through the introduction of non-toxic amino complex compounds and a method to synthesize such amino complex compounds from toxic industrial waste, both having remarkable economic benefits.

\section{Key problems for road construction in Russia}

\subsection{The influence of natural factors on the construction of roads on the clayey soils in Russia}

Soils can be categorized by their origin into the natural stratifications of the crust (coarse, sandy and silty-clayey) in a natural compact and humid state, formed over millions of years as a result of the destruction of the ancient mountain or sea rocks (lacustrine, silty, alluvial etc.) and areas of infill activity which appeared as a result of human activity [2]. The main problem for construction on frozen ground is frost heave. Typical heaving soils are lacustrine-glacial deposits (varved clayey sandy-loam soils, loams and clays), subglacial marine deposits (Yoldia's clays), sandy and loamy water saturated species of moraine deposits with weak structural links and others. When the humidity of these soils exceeds the critical value, freezing in winter leads to a significant increase in their volume (heaving) in $20 \mathrm{~cm}$ or more within the frozen zone.

A significant part of the road network in Russia is subject to deformation due to the frost heave of soils which has three contributing factors:

- the presence of heaving soils;

- intensive water sorption;

- slow and deep freezing of the soil under the road surface (to a depth of $0.5 \mathrm{~m}$ ).

Elimination of any of the above mentioned factors prevents heaving. Thus, the most effective way to prevent heaving is to replace the upper level of the roadbed with a sand layer $0.5-0.6 \mathrm{~m}$ thick with a filtration coefficient of no less than $1 \mathrm{~m}$ per day. However, the tendency of sandy layers to become silted over time necessitates the laying of anti-silting layers consisting of geosynthetic materials. In addition, the delivery of drainage materials entails extensive transportation costs. It would be more appropriate to stabilize the heaving soils through the introduction of binding materials, reagents and synthetic resins. Depending on the nature of the additives, the stabilised soil may take on the properties of waterproofing, heat insulating or serve as a frost protective layer. 
The arrangement of frost protective layers needs to be a mandatory condition for road maintenance in most climatic zones of the Russian Federation. Roads abroad (Canada, Scandinavian countries) that are located in areas of seasonal freezing are constructed only from non-heaving soils. In Russia, the construction of roads using heaving soils is allowed if the deformation of the road caused by frost heave does not exceed the allowable values.

\subsection{Features of the normative regulation for the road construction on the clayey soils of Russia}

Current Industry Road Codes and Standards 218.046-01, approved by the Russian highways state company "Avtodor", characterize frost heave using an indirect method - by grain size distribution and some physical parameters (humidity at the boundaries of plasticity etc.). However, the practice shows that granulometric data do not give a precise estimate of soil heave. Indirect methods do not take into account many factors influencing frost heaving. In particular, the value of frost heave can be modified by a factor of 4-8 with variation in the mineral composition of the clay fraction and by a factor of 4.5 with a change in the exchangeable cations' content [3]. In soils saturated with different cations (one-, two- and three-valent) both migration of water and heave caused by freezing grow with an increase in the valence of the cations. In strongly heaving soils, mainly silty, bulk ice accumulates in the upper layer of the roadbed. In hydrophobic soils in the absence of wetting, redistribution of water during freezing does not appear but only in the first cycle of freezing-thawing. In the repeated cycles a sharp decrease in ice segregation was found. In this case, virtually irreversible coagulation takes place and as a consequence of that heavy clay often turns, for example, into a sandy loam [2].

The use of water-repellent agents is one of the most reliable physicochemical methods for preventing heave. Water repellents cause maximum reduction in the surface energy of mineral particles, as well as preventing the migration of water into the zone of freezing significantly decreasing soil heave. In connection with the improvement of methods of hydrophobization of soils the study of this problem is being continued.

Clayey soils of the northern regions of the Russian Federation are usually in a frozen state and can move in their fluid state when thawing. Their use in road and airfield construction is complex due to cryogenic processes such as frost heave and frost cracking occurring in soils under the influence of alternating temperatures. The unsatisfactory road conditions resulting from frost heave of soil cause a high degree of wear on vehicles, excessive fuel consumption, many road accidents and exacerbate environmental problems. In this connection, there is an urgent requirement to improve the soil properties for their application as a building material. Directional changes in the state and properties of clayey soils can be achieved by introducing water-binding and hydrophobic surfactants, leading them to an irreversible transformation.

Asphalt concrete pavements are widely used in Russia for the construction of modern highways, airfields, port and storage areas and city streets. Their projected service life is considered to be 16-20 years. However, according to the 
Russian Road Research Institute "RosdorNII", the actual service life of asphalt concrete pavement of roads in Russia is 5-8 years and, according to the Federal Highway Agency of Ministry of Transport and Communication of the Russian Federation "Rosavtodor", even less - 2 years [4]. In this regard, the improvement of the quality of asphalt concrete pavements is a top priority task.

In order to conserve and protect natural resources it is necessary to create environmentally friendly and energy-saving technologies to process toxic industrial waste into non-toxic products that are multi-purpose. This work presents a method to synthesize non-toxic amino complex compounds developed by the authors from the toxic waste of chemical and metallurgical plants and a new technology for their application in road construction. Thus, together with the task of improving the properties of clayey soils, this work provides a solution for the recycling of waste that were previously subject to disposal due to their being an increasing environmental hazard.

\section{Application of amino complex compounds for increasing the sustainability of urban transport operation}

\subsection{Synthesis of amino complex compounds in Russia}

We propose a new technology for utilization of the tarry residue from the chemical industry created during the production of aromatic and aliphatic amines and their derivatives and the waste from metallurgy such as chlorides and sulphates of copper, zinc, iron and other metals. Instead of combustion or storage, we suggest using the waste for the synthesis of non-toxic multi-purpose amino complex compounds (ACC).

The ACC produced by the developed method are fine-crystalline powders of varying colours depending on the cation with a melting point no lower than $120^{\circ} \mathrm{C}$. ACC are stable in the air, do not cake in storage and may be kept without any special precautions for a long time. Analysis of the experimental batch has shown the absence of the free amine in it. Working with the ACC is not hazardous in hot weather as they decompose at high temperatures, not lower than $120^{\circ} \mathrm{C}$.

The innovativeness of the proposed industrial technology of ACC production from the toxic waste and their application as a processing aid to improve the quality of the highly-moist clayey soils used in construction has been documented by RU patents [5].

As an example, we present one of the methods of production of the amino complex compounds for soils melioration [5].

Iron-aniline complex compound $\mathrm{ACC} \mathrm{FeCl}_{2} \cdot 2 \mathrm{An}$ (An - aniline) was synthesized from the waste of the Berezniki chemical plant (residue after distillation of aniline) and the Berezniki Titanium-Magnesium Plant (solid chlorides from titanium production). Mixing the solid chlorides from titanium production and the distillation residue after distillation of aniline in molar ratio between $\mathrm{FeCl}_{2}$ and aniline (1.7-2.0):(1.5-1.7) was performed in a special mixer. After loading, the mixture was stirred for 10-15 minutes. The fine-grain product 
obtained was examined for content of free amine. The transportation and storage of ACC was carried out using plastic bags. The ACC synthesis was implemented at the Berezniki chemical plant.

\subsection{Influence of the amino complex compounds on the stickiness of the clayey soils}

A significant characteristic of clayey soil is its stickiness. Since sticking in the soil at a pressure of no more than $0.5-1.0 \mathrm{MPa}$ appears only when the moisture exceeds the lower limit of plasticity; it is evident that the stickiness value depends primarily on the water content in the soil surface layers. Sticking of the clayey soils to different surfaces under the usual loads starts at a moisture level of $68 \%$ to $75 \%$ and the maximal stickiness (depending on the dispersion and mineralogical composition of the soil) is observed at a moisture level of $19-33 \%$.

Stickiness shows a strong dependence on the content of the colloidal particles in the soil and on their composition. With an increase in clay particle content the stickiness increases to a specific limit at which any further increase in the content of these particles has little influence. For densification of highly-moist clayey soils it is necessary to eliminate their heavy stickiness which precludes the use of digging and soil mixing machines and carrier vehicles.

The high moisture content of clayey soils makes it difficult to compact them. However, soil consolidation through compaction is a necessary process in the construction of road bases. Highly-moist clayey soils are impossible to loosen, and, therefore, to apply to them binding cement and other binders. Clods of highly-moist soil formed in the process of loosening adhere to each other and to the working parts and undercarriage of machines. This leads to lost time and increased costs in irrigation and drainage, transport, airfield and other types of construction.

During the processes preparatory to building, earth-moving and construction machinery may be used (without special measures) only when the stickiness level of the moist soil is low. The excavation of clayey soils using scrapers is only feasible at a relative moisture content in the soil up to $0.70-0.72$; when using autograders with a front shovel - a relative moisture content of $0.70-0.75$. Bulldozers can operate on soils of any moisture content where there is sufficient adhesion of the machine undercarriage to the soil base. However, their performance significantly decreases with any increase in the stickiness. Thus, when excavating highly-moist soils the main priority is to reduce the extra stickiness and eliminate the strong adhesion to the working parts and undercarriage of machines or decrease the cohesiveness of individual units of the moist soil.

The study of changes in the stickiness of clayey soils in the presence of ACC was carried out depending on their mineral composition and moisture. The ACC additives were introduced into the moist soil in the amount of $0.5 ; 1.0 ; 1.5 ; 2.0 \%$ of the weight of the air-dry sample. On the base of the research data the dependences of the stickiness on the amount of introduced additive for the clayey soils with different moisture were defined. To reduce the stickiness of the heavy hydromical loam and kaolinite clay to the allowed maximum it is 
necessary to introduce $1.0-1.5 \%$ of ACC additive, for montmorillonite clay $1.5-2.0 \%$ (by weight of air-dry soil).

\subsection{Influence of the amino complex compounds on the frost heave of clayey soils}

To prevent the development of cryogenic processes in the construction and during the operational period, soil salinization by sodium and calcium chlorides is widely used. The presence of a solute in water lowers its freezing temperature. Increasing the content of soluble salts in soil increases the concentration of the pore solution and thereby substantially reduces the freezing point of the soil. However, due to their high solubility, the sodium and calcium chlorides over time wash out to the lower layers and contribute to the contamination of groundwater.

Solidifying the soil as a means of preventing frost heave is usually carried out by treating the soil with chemical reagents (for example with hydrofluosilicic acid) or industrial waste (for example with waste from the paper-pulp industry) with following mixing and compacting. One of the disadvantages of this method is the minor effect on the heaving properties of treated soils. The frost heave ratio of the hydrofluosilicic acid-treated clay is $2.5-1.3 \%$, while that of the clay treated by lingosulphonates is $2.1 \%$, which does not eliminate the swelling and heaving degree of treated clays corresponding to the II-III groups [6]. The toxicity of hydrofluosilicic acid and the need for large amounts of it for soil treatment and the increased leachability of lignosulfate in moist soils can also be regarded as negative consequences from this method.

Another known method to reduce frost heave is the injection of a fluid with a viscosity greater than that of water into the soil [7]. The drawback to this method is the complexity of the solution injection into argillaceous soils. The commonly used method is to treat the soil with Portland cement with ensuing mixing and compacting [6]. The disadvantages of this method are the long curing period (28 days) and the relatively significant consumption of scarce cement binder.

In contrast to the methods described above, the use of amino complex compounds for the treatment of the clayey soils gives a significant reduction in frost heave up to its complete elimination (frost heave ratio is zero). Effects of the treatment can be observed immediately in contrast, for example, to the cement whose application takes a long time (28 days) to show any effect, this being determined by the curing of the binder.

The influence of $\mathrm{ACC} \mathrm{FeCl}_{2} \cdot 2 \mathrm{An}$ on the frost heave of clayey soils was investigated in comparison with the effect of Portland cement 400. The hydromical loam with a plasticity of 0.12 was taken for study at the optimum moisture content and at the relative moisture of 0.8 . The study was carried out by the method described in "The instructions for design of paved roads" VSN 46-83 [6].

Loamy soil treated with a different amount of ACC was mixed to form a nonsticky, free-flowing homogeneous mass, ensuring ease of application for the next treatment. The resulting mixture was compacted in the special form of a cylindrical shape of $100 \mathrm{~mm}$ in diameter and $80 \mathrm{~mm}$ in height, consisting of 
stacked rings, by a hydraulic press at a compaction pressure of $15 \mathrm{MPa}$ for 3 min. Prepared samples in the forms were held for 1 and 28 days in a wet air atmosphere and then saturated with water to a state of complete water saturation (for 3 days) and tested for frost resistance while defining the frost heave ratio, which is equal to the ratio of the total amount of frost heaving after complete freezing (value of frosty lift) to the original height of the soil sample prior to freezing, given as a $\%$.

The samples treated with Portland cement 400 were prepared by the same method and held before being saturated with water for 1 and 28 days in a wet-air atmosphere to cure the cement binder. Table 1 shows the results of studying the effects of $\mathrm{ACC} \mathrm{FeCl}_{2} \cdot 2 \mathrm{An}$ and Portland cement 400 on the frost heave of the hydromical loam.

Table 1: Influence of amino complex compound and Portland cement on the frost heave of the clayey soil.

\begin{tabular}{|l|c|c|c|}
\hline \multirow{1}{*}{ Additive } & $\begin{array}{c}\text { Additive content, \% on the } \\
\text { mass of soil }\end{array}$ & \multicolumn{2}{|c|}{$\begin{array}{c}\text { Frost heave ratio } \mathrm{K}_{\mathrm{fh}}, \%, \\
\text { for exposure }\end{array}$} \\
\cline { 2 - 4 } & 0 & 1 day & 28 days \\
\hline \multirow{3}{*}{ Animo } & 1 & 5.8 & 5.8 \\
complex & 2 & 3.7 & 3.7 \\
compound & 2 & 1.7 & 1.6 \\
& 3 & 0.7 & 0.6 \\
& 4 & 0.06 & 0 \\
& 4 & 0 & 0 \\
Portland & 6 & 5.0 & 2.2 \\
cement 400 & 8 & 5.0 & 1.4 \\
& 12 & 5.0 & 0.9 \\
\hline
\end{tabular}

The test results show that the clayey soil which belongs to the heaving degree group IV $(\mathrm{Kfh}=5.8 \%)$ after treatment with ACC in the amount of $2.3-3.0 \%$ by weight of the soil is characterized by a frost heaving ratio of less than $1.0 \%$, which shifts it to group I of non-heaving soils. Moreover, the introduction of $3 \%$ of ACC into the soil virtually eliminates frost heave after 1 day of exposure (Kfh $=0.06 \%$ ) and after 28 days $\mathrm{Kfh}$ is equal to zero. For a similar effect when using Portland cement the required amount of additive is much more $(8-12 \%)$ and the effect occurs only after the 28-day period required for the curing of the cement $(\mathrm{Kfh}=0.9-0 \%)$. Reducing the frost heaving is not observed after one-dayexposure following treatment with the cement additive $(\mathrm{Kfh}=5.0 \%)$.

The optimal amount of ACC essential to the prevention of frost heave of clayey soil was defined as follows: the lower limit was defined from the condition that the reduction in frost heave when using ACC is no less than $20 \%$ effective than that when using Portland cement (even after 28 days), the upper limit is the amount of ACC additive that completely eliminates frost heave. These limits are $2.5-3.0 \%$ by weight of the soil. Consequently, the clayey soil treated by amino complex compound in the amount of 2.5 to $3.0 \%$ differs from 
the soil treated by $12 \%$ of Portland cement by a significant decrease in frost heave achieved immediately after the treatment.

In this regard, the application of amino complex compounds to prevent frost heaving of clay rocks allows:

- Extensive usage of local soils (heaving clays, including the clays with high moisture content) for road basis construction;

- Reduced consumption of natural materials (sand, gravel, crushed stone);

- Extensive use of waste from the chemical and metallurgical industries in road construction while reducing the application of scarce materials, such as Portland cement;

- The dependence of the soil properties on the weather conditions to be decreased due to the rapid effect following soil treatment with ACC.

\subsection{Amino complex compounds as a new component of asphalt concrete mixture}

Asphalt mixture for the surfaces and bases of highways includes bitumen, mineral filler and a surfactant additive. In order to improve the strength characteristics of asphalt and reduce water saturation in the mixture the ACC $\mathrm{FeCl}_{2} \cdot 2 \mathrm{An}$ obtained from the Berezniki chemical plant can be used as a surfactant additive.

The asphalt concrete mixture under investigation has the following ratio of components: mineral filler - 91.0-93.0 wt.\%; bitumen - 6.5-8.23; ACC - 0.170.33 .

Table 2 shows the characteristics of the proposed asphalt mixture, containing ACC in comparison to the asphalt mixture prepared with a separate introduction of aniline and $\mathrm{FeCl}_{2}$ (in the same amount as that of ACC). Additionally, Table 2 includes the data on the properties of the asphalt mixture, wherein the mixture of amine derivatives, reported in [8], was used as a surface-active additive. The data in Table 2 show that the ACC when used as a surfactant additive increases the strength of asphalt mixture and reduces its water saturation.

Table 2: Physicochemical properties of asphalt concrete mixtures containing different surfactants.

\begin{tabular}{|l|c|c|c|}
\hline \multirow{2}{*}{ Properties } & \multicolumn{2}{c|}{ Surfactant } \\
\cline { 2 - 4 } & $\begin{array}{c}\text { Developed } \\
\mathrm{FeCl}_{2} \cdot 2 \mathrm{An}\end{array}$ & $\begin{array}{c}\mathrm{FeCl}_{2} \\
\mathrm{C}_{6} \mathrm{H}_{5} \mathrm{NH}_{2} \mathrm{An}\end{array}$ & $\begin{array}{c}\text { Mixture of amine } \\
\text { derivatives [6] }\end{array}$ \\
\hline $\begin{array}{l}\text { Ultimate compressive } \\
\text { strength, } \mathrm{R}_{\mathrm{pr}}, \mathrm{MPa}:\end{array}$ & & & \\
$\begin{array}{l}\text { at } 20^{\circ} \mathrm{C} \\
\text { at } 50^{\circ} \mathrm{C}\end{array}$ & $3.95-4.21$ & $3.26-3.45$ & 3.41 \\
$\begin{array}{l}\text { Factor of water } \\
\text { resistance }\end{array}$ & $1.81-1.99$ & $1.36-1.57$ & 1.46 \\
$\begin{array}{l}\text { Factor of prolonged } \\
\text { water resistance }\end{array}$ & $0.96-0.98$ & $0.91-0.94$ & 0.93 \\
Water saturation, vol. \% & $0.93-0.94$ & $0.87-0.90$ & 0.91 \\
\end{tabular}




\section{Conclusions}

Because of their many properties, amino complex compounds can be used in various spheres of the national economy. In this paper, the study related to their use in improving the reliability of road surfaces is presented. It was shown that metal-aniline complex compounds can be used in the production of consistently reliable building material on a base of clayey soils with a high moisture content. The variable properties of clayey soils treated with amino complex compounds are of interest from both a theoretical aspect and a practical one.

The paper presents a new technology for the production of metal-amine complex compounds from toxic industrial waste. This simplifies the process and reduces the cost of synthesis ensuring the long-term storage capability and the non-toxicity of the derived product.

Field-scale tests of the new composite material on a base of high moisture content clayey soils and the amino complex compounds have shown that it is effective in increasing the strength and decreasing the deformability of the ground base for modern highway surfaces. Amino complex compounds should be considered as a promising technological additive that can dramatically change the state of high-clay soils making them coarse-textured which facilitates their further treatment with binder materials. Amino complex compounds in the amount of 2.5-3.0\% (by weight of soil) almost completely prevent frost heave of clayey soil, which in the absence of the amino complex additive is characterized by a frost heave ratio of $5.8 \%$. The amino complex compounds retain their properties during prolonged storage in warehouses that have no special measures for packing and storage. Their use in the construction of roads increases the sustainability of urban transport operation. The use of amino complex compounds, synthesized from toxic industrial waste and utilized in the production of new non-toxic composite material gives a strongly pronounced positive environmental effect.

\section{References}

[1] Cherepanov, B.M. \& Korotkikh, S.G., Influence of the frost heave forces on the highway maintenance, Polsunov's bulletin, Vol. 1-2, pp. 95-98, 2007.

[2] Ukrainchuk, A. Yu., Soil stabilization by the method of application of the hydrophobic additives for decreasing the soil heaving, Young scientist, Vol. 1 (1), pp. 45-48, 2012.

[3] Shorin, V.A., Kagan, G.L., Vel'sovskiy, A.Yu. \& Rogozin, N.N., Development of the method of characterisation of the having properties of soil, Modern scientific and technical problems in the transport construction: Proceedings of All-Russian Scientific and Technical Conference. Kasan: KSUAE, 2007.

[4] Borisov, S.M., Hard about hard surfaces (In Russian: Жёстко о жёстких покрытиях), Highways, Vol. 3, pp. 46-47, 2009. 
[5] Maslennikova, I.S. \& Maslennikova, T.Yu., The method for producing of the water-binder for disperse alumina silicate systems: RU patents №2041877, №2041880, №2041881, №2041882, №2041883, 1995.

[6] Maslennikova, I.S., New technology of increasing the reliability of building structures - St. Petersburg: SPSUEE, 2012.

[7] Tsutomu, T., Method of preventing ground from freezing and expanding: JPS6039814 (B2), 1985-09-07.

[8] Gordon, K.T., Waybe, G.D. \& Murl, G.L., Metal anime complexes for improving the bond strength properties of asphalt: EP0125852 (A1), pp. 1121, 1985. 